\title{
PEMIKIRAN EKSPLORATIF TENTANG KEMUNGKINAN HUBUNGAN ANTARA GEMPABUMI ACEH 26 DESEMBER 2004, PERUBAHAN POLA GEOID, DAN ERUPSI GUNUNGAPI SINABUNG 2010-2017
}

Kirbani Sri Brotopuspito

\section{Ringkasan}

Aktivitas volkanik Gunugapi Sinabung sejak 27 Agustus 2010 yang menerus sampai dengan 2017 telah menarik banyak perhatian, karena Gunungapi ini sudah tidak aktif dalam kurun waktu yang lama,yaitu lebih dari 400 tahun dari tahun 1600. Melanjutkan penelitian pada tahun 2016, penulis ingin mengkaji apa penyebab Gunungapi Sinabung aktif kembali. Maka dari itu, penelitian ini mengkaji kemungkinan penyebab aktifnya kembali Gunungapi Sinabung, terutama berdasarkan kejadian gempabumi Aceh 2004 dan Nias 2005 yang menyebabkan terjadinya undulasi geoid rendahan di Selat Malaka di sebelah timur Sumatra Utara, dan keberadaan Gunungapi Sinabung yang tidak terlalu jauh dari komplek Kaldera Danau Toba. Pemodelan komplek kantong magma Gunungapi Toba berdasarkan hasil tomografi seismik mengindikasikan adanya zona rasio kecepatan gelombang $\mathrm{P}$ dan $\mathrm{S}$ $\left(v_{p} / v_{s}\right)$ rendah pada bagian yang berdekatan dengan lokasi Gunungapi Sinabung, yang dapat ditafsirkan sebagai buatan dengan material lelehan. Hal ini juga akan dikaji kemungkinan terjadinya aliran material lelehan/magma ke atas di bawah Gunungapi Sinabung, yang mungkin dipicu oleh adanya pembukaan rekahan akibat tarikan gaya gravitasi oleh undulasi geoid rendahan yang terjadi setelah gempabumi Aceh 2004 dan Nias 2005.

Kata Kunci : Gunungapi Sinabung, Komplek Kantong Magma Toba, Undulasi Geoid Rendahan, Gempabumi Aceh 2004 dan Nias 2005.

\section{Abstract}

The volcanic activity of Sinabung Gunugapi since August 27, 2010 which continues until 2017 has attracted a lot of attention, because this volcano has been inactive for a long time, which is more than 400 years from 1600. Continuing research in 2016, the authors want to examine the causes Sinabung volcano is active again. Therefore, this study examines the possible causes of reactivation of Sinabung Volcano, especially based on the events of the Aceh 2004 earthquake and Nias 2005 which caused low geoid undulations in the Malacca Strait to the east of North Sumatra, and the existence of Sinabung Volcano which is not too far from the Lake Caldera complex Toba. Modeling of the Toba Volcanic magma pouch complex based on the results of seismic tomography indicates a low $\mathrm{P}$ and $\mathrm{S}\left(v_{p} / v_{s}\right)$ wave velocity ratio zone in the part adjacent to the location of the Sinabung Volcano, which can be interpreted as artificial with melt material. This will also be examined for the possibility of the flow of melt / magma material upwards under Sinabung Volcano, which may be triggered by the opening of fractures due to the pull of gravitational forces by the low geoid undulation that occurred after the Aceh 2004 earthquake and Nias 2005.

Keywords: Sinabung Volcano; Toba Magma Bag Complex; Undulation of Geoid Lowers Aceh 2004 Earthquake and Nias 2005. 


\section{Pendahuluan}

Gunungapi Sinabung secara volkanik aktif kembali pada 27 Agustus 2010 setelah tidak aktif sejak tahun 1600 [8]. Ada catatan dari Global Volcanism Network(GVN) bahwa Gunungapi Sinabung aktif dengan erupsi yang tidak jelas (uncertain) pada tahun 1881. PVMBG juga mencatat adanya kegiatan solfatarik di puncak lereng atas Gunungapi Sinabung pada tahun 1912. GVN menyatakan Erupsi Gunungapi Sinabung pada 27 Agustus 2010 dan 15 September 2013 mempunyai skala VEI(Volcano Explosivity Index) 2. Walaupun skala erupsi Gunungapi Sinabung relatif rendah bila dibandingkan errupsi Gunungapi Merapi 2010 dan Gunungapi Kelut 2014 yang berskala VEI 4, tetapi ada kesan aktivitas volkaniknya berlangsung sudah cukup lama, yaitu sudah sekitar 7 tahun hampir secara terus-menerus. Hal ini yang menyebabkan penulis merasa terpanggil untuk mencari jawaban, apakah penyebab aktivitas volkanik yang berkepanjangan ini?

Penelitian sebelumnya [5] yang dilakukan penulis adalah melakukan pengkajian hubungan spasial dan temporal antara gempabumi Aceh 2004, Nias 2005, perubahan geoid, dan perubahan tegangan di daerah Kepulauan Andaman dan Aceh, Sumatera Utara. Dari penelitian tersebut didapatkan kesimpulan bahwa gempabumi Aceh 2004 telah menimbulkan perubahan geoid, yang dapat ditafsirkan terjadinya perubahan distribusi massa di bawah permukaan bumi terutama di daerah mantel bagian atas. Walaupun demikian hal tersebut tidak dapat ditafsirkan bahwa tidak ada kemungkinan perubahan distribusi massa atau struktur geologi. dan tegangan di bagian kerak bumi. Sehingga perubahan geoid dalam skala yang luas akibat Gempabumi Aceh dapat dikaji kemungkinannya menjadi penyebab aktivitas volkanik di Gunungapi Sinabung. Maka dari itu, penelitian ini bertujuan: mengkaji aktivitas volkanik Gunungapi Sinabung dan mengkaji kemungkinan penyebab erupsi Gunungapi Sinabung, dengan harapan untuk mendapatkan jawaban pemikiran eksploratif tentang penyebab erupsi Gunungapi Sinabung. Pemikiran sementara: Erupsi Gunungapi Sinabung disebabkan oleh pembukaan sumbat lava akibat adanya deformasi perekahan conduit. Perekahan conduit terjadi adanya gaya tarikan undulasi rendahan geoid akibat Gempabumi Aceh 2004.

\section{Studi Pustaka}

Gunungapi Sinabung yang berlokasi di sekitar 40 $\mathrm{km}$ di sebelah barat-laut dari Danau Toba, juga

Full list of author information is available at the end of the article ${ }^{*}$ Equal contributor relative tidak terlalu jauh yaitu sekitar $250 \mathrm{~km}$ di sebelah timur-laut dari sumber Gempabumi Aceh 26 Desember 2004. Kesimpulan penelitian eksploratif Kirbani (2016) adalah: 1. Kejadian gempabumi Aceh 26 Desember 2004 dan Nias 28 Maret 2005 diikuti oleh perubahan pola medan gravitasi, undulasi geoid, dan tegangan di daerah sekitarnya. 2 . Proses relaksasi medan gravitasi dan undulasi geoid pasca-gempabumi Aceh 26 Desember 2004 dan Nias 28 Maret 2005 memerlukan memerlukan waktu 0.7 tahun. Gunungapi Sinabung (gambar 1) berada di sebelah selatan relatif di dekat tepi undulasi geoid negtaif (" coseismic geoid low", [3]) akibat Gempabumi Aceh 2004 dan Nias 2005 tersebut. Di samping itu, Gunungapi Sinabung juga terletak tidak terlalu jauh disebelah utara Danau Toba yang merupakan gunungapi besar (super volacano). Gunungapi Toba mempunyai kemungkinan sistem kantong magma yang mencakup atau sangat berdekatan dengan Gunungapi Sinabung. Hal ini terlihat dari hasil tomografi seismik yang dilakukan oleh Koulakov dkk. (2009). Terlihat pada Gambar 2, bahwa terdapat zona rendah rasio kecepatan gelombang $\mathrm{p}$ dan $\mathrm{s}$ (low $v_{p} / v_{s}$ zone) di bawah permukaan Komplek Danau Toba, yang bagian tepi sebelah utara sangat berdekatan dengan posisi Gunungapi Sinabung. Zona rendah rasio $v_{p} / v_{s}$ beraarti zona yang memiliki batuan dengan rigiditas yang rendah, sehingga dapat ditafsirkan merupakan zona keberadaan magma volkanik. Pernyataan ini juga diperkuat dengan hasil pemodelan bawah permukaan Danau Toba berdasarkan tomografi gelombang permukaan [4]. Maka dari itu penulis akan mengembangkan pemikiran eksploratif, kemungkinan keberadaan sistem komplek magma di bawah Danau Toba dan sekitarnya (termasuk Gunungapi Sinabung) telah terdeformasi oleh adanya undulasi geoid rendah yang terjadi akibat Gempabumi Aceh 2004 dan Nias 2005, sehingga Gunungapi secara volkanik aktif kembali pada tahun 2010.

\section{Metode Penelitian}

Mengingat waktu penelitian yang hanya 6 bulan, maka peneliti akan melaksanakan langkah-langkah penelitian disajikan dalam bentuk diagram alir pada Gambar 3 sbb.:

\section{Hasil dan Pembahasan}

Peta tiga dimensi geoid global yang di hasilkan oleh satelit CHAMP [2] konsisten memperlihatkan cekungan undulasi geoid di sekitar ujung selatan India dan cembungan di kawasan Indonesia. Geoid merupakan undulasi bidang ekipotensial medan gravitasi yang paling mendekati sferoida 


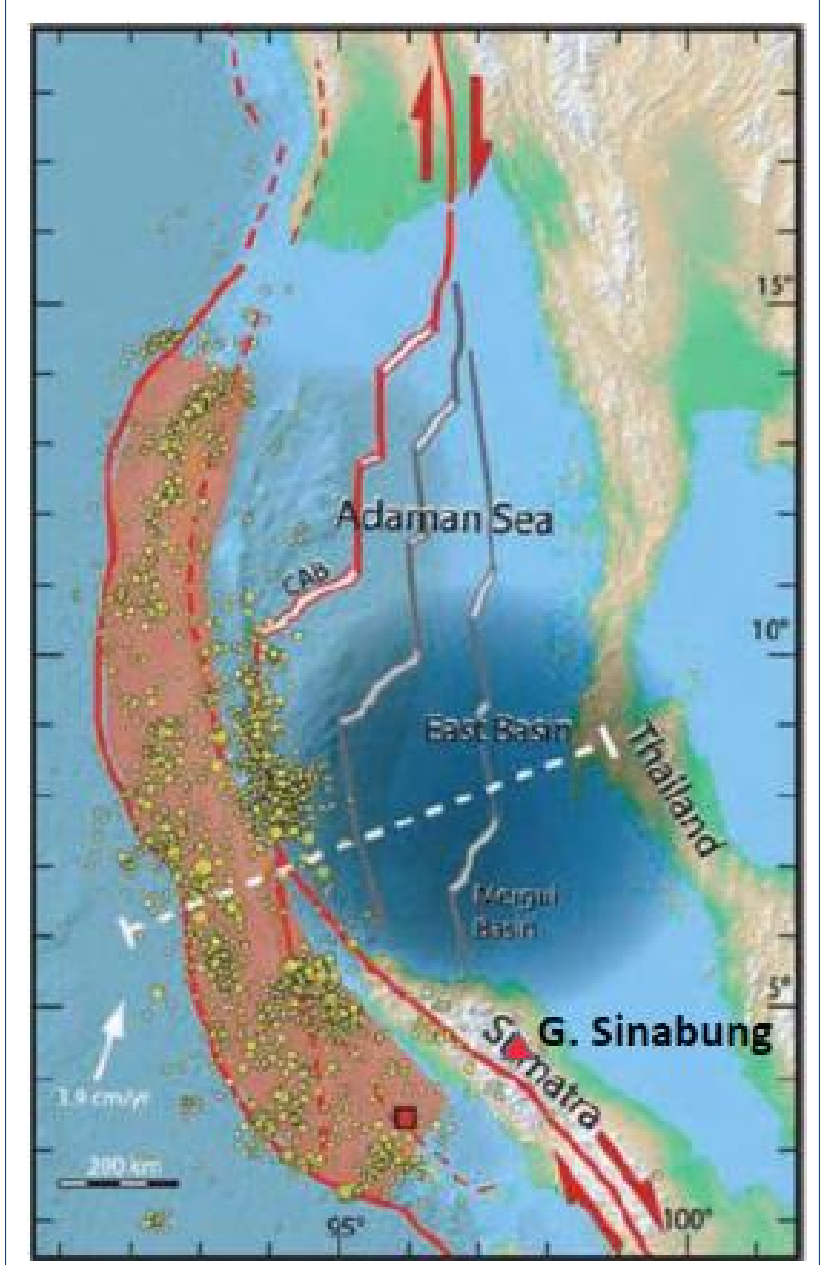

Gambar 1 Posisi Gunungapi Sinabung yang berada di sebelah selatan tepi undulasi geoid rendah ("coseismic geoid low", [3]) akibat Gempabumi Aceh 2004 dan Nias 2005.

referensi. Cembungan geoid di kawasan Indonesia yang merupakan perwujudan keadaan permukaan bidang ekipotensial gravitasi maksimum, mempunyai konsekuensi menjadi kawasan yang tidak stabil. Cekungan geoid yang merupakan perwujudan keadaan permukaan bidang ekipotensial gravitasi minimum, mempunyai konsekuensi menjadi kawasan yang stabil. Gejala tersebut terbukti mempunyai implikasi pada pola tegangan permukaan kerakbumi yang rumit di kawasan Indonesia yang tidak stabil karena merupakan daerah geoid minimum [5]. Rai dkk 2015, menyatakan adanya implikasi kawasan tegangan permukaan kerakbumi dengan kejadian gempabumi di kawasan Teluk Benggala. Richard dkk, 1984 juga menyatakan adanya hubungan antara variasi elevasi geoid dengan tegangan litosfer permukaan kerakbumi di dalam kaitannya dengan geodinamika. Akibat dari gempabumi Aceh 26 Desember 2004 dan Nias 28
Maret 2005, terjadi perubahan regangan dan tegangan geser, normal, dan kompresi.

Aktivitas Gunungapi Sinabung yang dimulai dari erupsi 27 Agustus 2019 dengan skala VEI 2 [8] berlanjut dengan beberapa kali erupsi dan berbagai jenis aktivitas kegunungapian seperti pembentukan kubah lava dan awan panas akibat guguran kubah lava sampai dengan 2017.

Posisi Gunungapi Sinabung yang berada pada $3^{\circ} 10^{\prime}$ Lintang Utara dan $98^{\circ} 23,5^{\prime}$ Bujur Timur di Sumatera Utara ternyata tepat di atas zona rendah rasio kecepatan gelombang $\mathrm{p}$ dan $\mathrm{s}$ (low $v_{p} / v_{s}$ zone)yang rendah [1] [11] [6].

Gempabumi Aceh 26 Desember 2004 mengakibatkan terjadinya uplift di barat dan subsidencedi barat Pulau Sumatera [7], juga mengakibatkan terjadinya zona geoid rendahan di Selat Malaka [3].

Keempat pernyataan di atas memungkinkan penulis untuk menyusun konsep kerangka berfikir sebagai berikut: Sumatera Utara yang berada di antara zona geoid rendah di sebelah Barat dan zona geoid tinggi di sebelah Timurnya mengalami tegangan. Di samping itu lempeng tektonik Indo-Australia yang menyusup di bawah Sumatera secara miring ke arah Timur Laut dengan kelajuan sekitar $5 \mathrm{~cm} /$ tahun juga selalu menambah tegangan tersebut. Klimaks terjadi pada saat Gempabumi Aceh 26 Desember 2017, yang merupakan pelepasan energi sekitar $10^{28}$ erg (Kirbani,2011). Gempabumi Aceh 26 Desember 2017 juga menimbulkan uplift di sebelah Barat Sumatera dan subsidence di sebelah Timur Sumatera, juga mengakibatkan terjadinya undulasi geoid rendahan di Selat Malaka. Gunungapi Sinabung yang tidak aktif sejak 1600 [8] yang juga terletak di atas zona rendah rasio kecepatan gelombang $\mathrm{p}$ dan $\mathrm{s}$ (low $\left.v_{p} / v_{s} z o n e\right)$ [1] [11] [6], mengalami regangan akibat tarikan zona undulasi rendahan di Selat Malaka, sedemikian rupa sehingga mengakibatkan keluarnya magma dari kantong magmanya (zona rendah rasio kecepatan gelombang $\mathrm{p}$ dan $\mathrm{s}\left(\right.$ low $v_{p} / v_{s}$ zone $) \mathrm{dkl}$. Erupsi Gunungapi Sinabung 27 Agustus 2010 sampai dengan 2017 [8].)

\section{Kesimpulan}

Kemungkinan kerangka berfikir penyebab aktifnya kembali Gunungapi Sinabung sebagai berikut: Sumatera Utara yang berada di antara zona geoid rendah di sebelah Barat dan zona geoid tinggi di sebelah Timurnya mengalami tegangan. Di samping itu lempeng tektonik Indo-Australia yang menyusup di bawah Sumatera secara miring ke arah Timur Laut dengan kelajuan sekitar $5 \mathrm{~cm} /$ tahun juga selalu menambah tegangan tersebut. Klimaks terjadi pada saat Gempabumi Aceh 26 Desember 2017, 


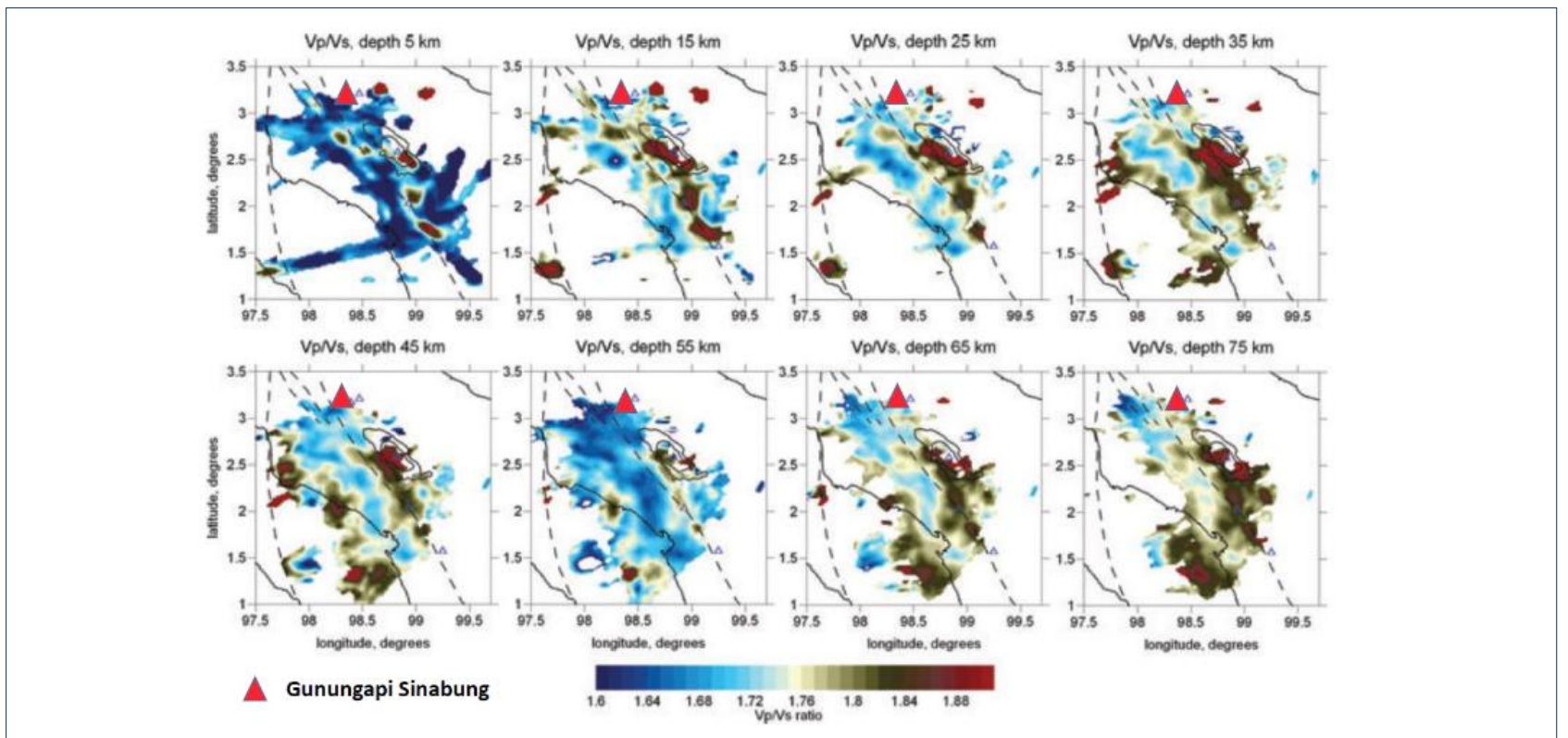

Gambar 2 Posisi Gunungapi Sinabung $(\Delta)$ terdapat berada di sebela utara tepi zona rendah rasio kecepatan gelombang $\mathrm{p}$ dan $\mathrm{s}$ (low $v_{p} / v_{s}$ zone), dari hasil tomografi seismik bahwa permukaan Komplek Danau Toba dan sekitarnya (Gambar dimodifikasi dari [6])

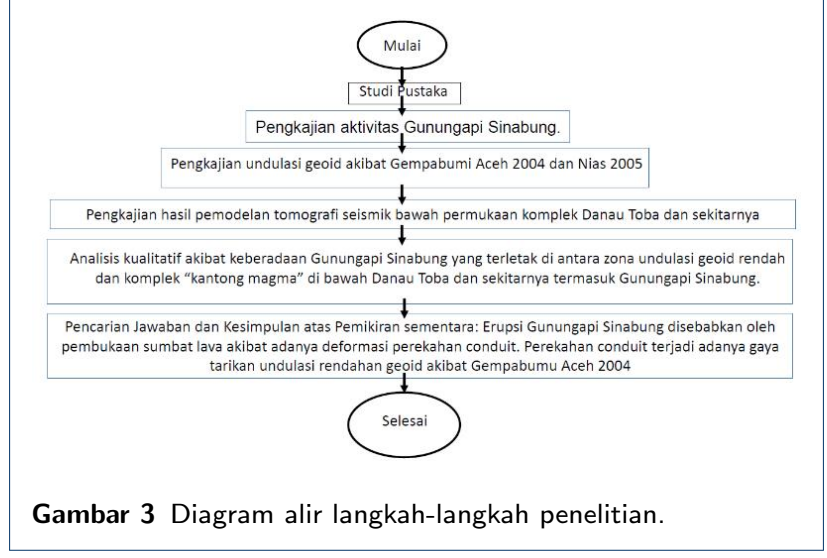

yang merupakan pelepasan energi sekitar $10^{28}$ erg (Kirbani,2011). Gempabumi Aceh 26 Desember 2017 juga menimbulkan uplift di sebelah Barat Sumatera dan subsidence di sebelah Timur Sumatera, juga mengakibatkan terjadinya undulasi geoid rendahan di Selat Malaka. Gunungapi Sinabung yang tidak aktif sejak 1600 [8] yang juga terletak di atas zona kecepatan gelombang seismik primer $\left(v_{p}\right)$ dan sekunder $\left(v_{s}\right)$ yang rendah [1] [11] [6], mengalami regangan akibat tarikan zona undulasi rendahan di Selat Malaka, sedemikian rupa sehingga mengakibatkan keluarnya magma dari kantong magmanya (zona kecepatan gelombang seismik primer $\left(v_{p}\right)$ dan sekunder $\left(v_{s}\right)$ yang rendah dkl. Erupsi Gunungapi Sinabung 27 Agustus 2010 sampai dengan 2017).

\section{Penulis}

Kirbani Sri Brotopuspito

Dari :

Program Studi Geofisika, Departemen Fisika, Fakultas Matematika dan Ilmu Pengetahuan Alam, Universitas Gadjah Mada

Alamat :

Sekip Utara, Kotak Pos BLS 21, Yogyakarta 55281

email : kirbani@ugm.ac.id

\section{Pustaka}

1. Atin Nur Aulia, Andri Dian Nugraha, Novianti Indrastuti, and Hendra Gunawan, 2017. Seismic tomography imaging beneath Sinabung Volcano, North Sumatra area, Indonesia Conference Paper in AIP Conference Proceedings 1857(1):070003 • July 2017. DOI: 10.1063/1.4987091. Conference: INTERNATIONAL SYMPOSIUM ON EARTH HAZARD AND DISASTER MITIGATION (ISEDM) 2016: The 6th Annual Symposium on Earthquake and Related Geo-hazard Research for Disaster Risk Reduction.

2. GFZ 2011, http ://www.gfz-potsdam.de/en/mediacommunication/mediathek/imagegalleries/geoid - the - postdam - gravity potato/Goid: The Postdam Gravity Potato; diakses 3 Oktober 2017.

3. Isabelle Panet, Valentin Mikhailov, Michael Diament, Fred Pollitz, Geoffrey King, Olivier de 
Viron, Mathias Holschneider, Richard Biancale and Jean-Michel Lemoine, 2007, Coseismic and post-seismic signatures of the Sumatra 2004 December and 2005 March earthquakes in GRACE satellite gravity, Geophys.J.Int. (2007) 171, 177-190. DOI: 10.1111/j.1365-246x.2007.03525.x.

4. Jaxybulatov, K., N.M. Shapiro, I. Koulakov, A.Mordret, M. Landes, dan C. Sen-Schonfelder, 2014, A Large Magmatic Still Complex beneath the Toba Caldera, Science 345, 617 (2014); DOI: 10.1126/science. 1258283.

5. Kirbani Sri Brotopuspito 2016, Penelitian Eksploratif tentang Kemungkinan Kolerasi Spasial Kejadian Gempabumi Aceh 2004, dengan Bentuk Geoid, dan Peta Tegangan Permukaan Kerak Bumi, Laporan Penelitian Dosen Jurusan Fisika FMIPA-UGM.

6. Koulakov, I., Tedi Yudistira, Birger-G. Luehr, dan Wandono, 2009, P, S Velocity, and $V_{p} / V_{s}$ Ratio Beneath theToba Caldera Complex (Northern Sumata) from Local Earthquakes Tomography, Journal G. Int., 2009; DOI: 10.1111/j.1365-246X2009.4114.x.

7. Meltzner Aron J., Kerry Sieh, Michael Abrams, Duncan C. Agnew, Kenneth W. Hudnut, Jean-Philippe Avouac, and Danny H. Natawidhaha, 2006, Uplift and subsidence associated with the great Aceh-Andamanearthquake of 2004, JOURNAL OF GEOPHYSICAL RESEARCH, VOL. 111, B02407, doi:10.1029/2005JB003891, 2006.

8. PVMBG, 2010, 2013, dan 2017, Laporan Bulanan Aktivitas gunung Sinabung Sumatera Utara.

9. Rai, A.K., S. Tripathy, and S.C. Sahu, The May 21st, 2014 Bay of Bengal earthquake: implications for intraplate stress regime, Current Science, Vol. 108, 1706 No. 9, 10 May 2015.

10. Richard Yanick, Luce Fleitout, dan Calude Froidevaux, 1984, Geoid heights and lithosperic stress for a dynamic Earth. Annales Gephysicae, 1984, vol. 2, 3, pages 167-286.

11. Stankiewicz Jacek. Trond Ryberg, Christian Haberland, Fauzi, and Danny Natawidjaja, 2010, Lake Tobavolcano magma chamber imaged by ambient seismicnoise tomography, GEOPHYSICAL RESEARCH LETTERS, VOL. 37, L17306, doi:10.1029/2010GL044211, 2010. 